Communications in Physics, Vol. 24, No.3S1 (2014), pp. 22-28

DOI:10.15625/0868-3166/24/3S1/5073

\title{
PHOTOLUMINESCENCE QUENCHING OF NANOCOMPOSITE MATERIALS USED FOR ORGANIC SOLAR CELLS
}

\author{
TRAN THI THAO, DO NGOC CHUNG, NGUYEN NANG DINH \\ University of Engineering and Technology, Vietnam National University, Hanoi \\ VO-VAN TRUONG \\ Department of Physics, Concordia University, \\ 1455 de Maisonneuve Blvd W., Montreal Quebec, Canada H3G 1M8 \\ E-mail:dinhnn@vnu.edu.vn \\ Received 04 June 2014 \\ Accepted for publication 24 August 2014
}

\begin{abstract}
In this work, we have studied the photoluminescence (PL) quenching of two polymeric composites, poly[2methoxy-5-(2-ethylhexyloxy)-1,4-phenylenevinylene] (MEH-PPV) and poly(3-hexylthiophene) (P3HT) in presence of $n c-\mathrm{TiO}_{2}$ particles by $\mathrm{PL}$ - spectroscopy. $\mathrm{PL}$ quenching values are $19.2 \%$ and $45.5 \%$, for $\mathrm{MEH}-\mathrm{PPV}+n c-\mathrm{TiO} \mathrm{O}_{2}$ and $\mathrm{P} 3 \mathrm{HT}+n c-\mathrm{TiO}_{2}$, respectively. The obtained results on the relationship of PL quenching and photoelectrical efficiency (PCE) of an OSC showed that the quenching coefficient of a semiconducting polymer can be considered as apreliminary criterion for choosing an appropriate polymeric composite being used for OSC preparation. Under illumination of solar energyof $56 \mathrm{~mW}^{\mathrm{cm}} \mathrm{cm}^{2}, \mathrm{P} 3 \mathrm{HT}+\mathrm{TiO}_{2}$ based OSC possess $\mathrm{FF}, V_{O C}, J_{S C}$ and PCE of $0.64,0.243 \mathrm{~V}, 1.43 \mathrm{~mA} / \mathrm{cm}^{2}$ and $0.45 \%$, respectively.
\end{abstract}

Keywords: photoluminescence $(\mathrm{PL})$ quenching, nc-TiO $2, \mathrm{MEH}-\mathrm{PPV}+n c-\mathrm{TiO}_{2}, \mathrm{P} 3 \mathrm{HT}+n c-\mathrm{TiO} \mathrm{O}_{2}$, heterojunctions, organic solar cell (OSC).

\section{INTRODUCTION}

Recently, solar cells based on organic materials are increasingly interesting because of their possibility to reduce the fabrication cost [1-3]. Organic solar cells (OSCs) should have the following features: a strong light absorption over the whole solar spectrum; an appropriate energetic distance between the highest occupied molecular orbital (HOMO) and the lowest occupied molecular orbital (LUMO) of polymer to form a high open circuit voltage; a high and balanced electron and hole mobility in the polymer layer $[4,5]$. When sufficient energy is applied to a semiconducting polymer, electrons from the HOMO level (valence band) are excited to the LUMO level (conduction band). This excitation process leaves holes in the valence band, and thus creates "electronhole-pairs" (EHPs). When these EHPs are in intimate contact (i.e., the electrons and holes have not dissociated) they are termed "excitons". To develop viable devices such as OSCs there are two main approaches that have been developed [6]: (i) the donor-acceptor bilayer, commonly achieved by vacuum deposition of molecular components, and (ii) the so-called bulk heterojunction (BHJ),

(C)2014 Vietnam Academy of Science and Technology 
consisting of a bicontinuous composite of donor and acceptor phases. Among numerous electrically conducting polymers, poly[2-methoxy-5-(2-ethylhexyloxy)-1,4-phenylenevinylene] (MEHPPV) with an energy bandgap of $2.2 \mathrm{eV} \mathrm{[7])} \mathrm{and} \mathrm{poly(3-hexylthiophene)} \mathrm{(P3HT)} \mathrm{are} \mathrm{mostly} \mathrm{used}$ for organic electronic devices such as light emitting diodes (OLED) andOSCs, respectively. The BHJ solar cells based on poly(3-hexylthiophene) (P3HT) with an energy bandgap of $1.9 \mathrm{eV}$ [8] and the fullerene derivative [6,6]-phenyl-C61-butyric acid methyl ester (PCBM) - that are currently considered to be the ideal acceptors for OSC -have been widely investigated. PCBM have an energetically deep-lying LUMO [9], which endows the molecule with a very high electron affinity relative to the numerous potential organic donors like P3HT.However, the efficiency of an organic solar cell until now is considerably low; this is usually attributed to the strong decay of the excitons which are generated in the donors/acceptors junctions owing to the illumination of solar radiation. The excitons decay can be diminished by the creation of either appropriate heterojunctions or nanocomposite layers. This results in the charge separation, i. e. generated electrons and holes move in opposite directions, and consequently the luminous quenching occurs. Thus by characterization of the quenching behavior of polymeric composite materials, one can have preliminary evaluations on the photoelectrical conversion efficiency of the materials used for OSCs.

This work presents results of our recent research on the luminous quenching properties of two conducting polymers (namely MEH-PPV and P3HT) with embedding of nanocrystalline $\mathrm{TiO}_{2}$ $\left(\right.$ nc- $\left.\mathrm{TiO}_{2}\right)$ particles. The performance of OSCs based on two types of the nanocomposites is also presented.

\section{EXPERIMENTAL}

To compare the photoactive properties of MEH-PPV and P3HT nanocomposites, two types of OSCs based on MEH-PPV and P3HT were prepared, using ITO with a sheet resistance of $10 \Omega$. The ITO-coated glass substrates used for spin coating nanocomposite films were ultrasonically cleaned in distilled water, followed by cleaning in ethanol and acetone. To deposit the composite layers onto ITO, MEH-PPV and P3HT solutions were prepared by dissolving MEH-PPV and P3HT powders, respectively in xylene and chlorobenzene as follows: $10 \mathrm{mg}$ of MEH-PPV in 1 $\mathrm{ml}$ of xylene and $8 \mathrm{mg}$ of $\mathrm{P} 3 \mathrm{HT}$ in $1 \mathrm{ml}$ of chlorobenzene. Then, $\mathrm{TiO}_{2}$ nanoparticles with $5 \mathrm{~nm}$ and $15 \mathrm{~nm}$ in size were embedded, respectively in MEH-PPV and P3HT solutions according to a same weight ratio $\mathrm{TiO}_{2} /$ polymer of 0.05 (namely $5 \mathrm{wt}$. \%), further referred to as MTC and PTC.To obtain a homogenous dispersion of $\mathrm{TiO}_{2}$ in polymers, the solutions were mixed for 8 hours by using magnetic stirring. These liquid composites were then used for spin-coating. The conditions for spin-coating are as follows: a delay time of $120 \mathrm{~s}$, a rest time of 30s, a spin speed of $1500 \mathrm{rpm}$, and an acceleration of $500 \mathrm{rpm}$, and finally a drying time of $2 \mathrm{~min}$. The films used for photoluminescence (PL) characterization were spin-coated onto glass pieces with $1.2 \mathrm{~cm} \times$ $1.2 \mathrm{~cm}$ in size. For the acceptor layer, a $50 \mathrm{~nm}$-thick PCBM layer was then spin-coated onto the nanocomposite layers. To dry the films, the samples were put in a flow of dried gaseous nitrogen for 12 hours. Then a $70 \mathrm{~nm}$-thick Al-electrode on the top was thermally evaporated in a vacuum of $1.33 \times 10^{-3} \mathrm{~Pa}$, using a mask with windows of $4 \mathrm{~mm} \times 5 \mathrm{~mm}$ in size. Therefore, the active area of a cell is $0.20 \mathrm{~cm}^{2}$. By this way, two type of organic solar cells (OSC) which have structure of $\mathrm{Al} / \mathrm{PCBM} / \mathrm{MTC} / \mathrm{Al}$ and Al/PCBM/PTC/Al were prepared, as shown in Fig. 1. 
Absorption spectra of the samples were carried-out on a Jasco V-570 UV-Vis-Nir spectrometer. Quenching effect of the nanocomposite layers was studied by photoluminescence spectra on a FLuoroMax-4 spectrofluorometer, using radiation of Xe-lamp for excitation. The performance of the OSCs was carried-out on an AutoLab-Potentiostat PGS-12 electrochemical unitwith an illumination power of $56 \mathrm{~mW} / \mathrm{cm}^{2}$ taken from "Sol 1A" Newport source which provides an energy spectrum similar to the solar one.

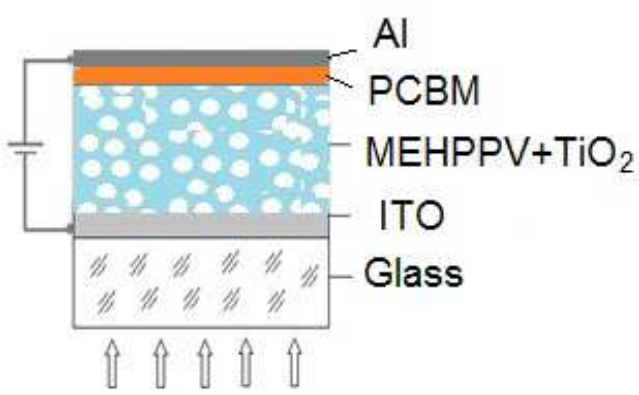

(a)

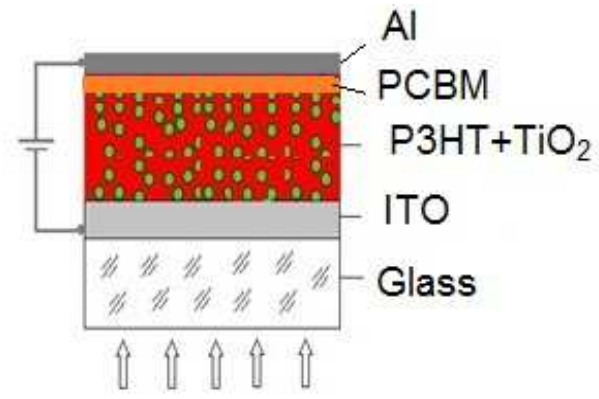

(b)

Fig. 1. Schematic drawing of OSCs based on nanocomposite of $\mathrm{MEH}-\mathrm{PPV}+\mathrm{TiO}_{2}$ (a) and $\mathrm{P} 3 \mathrm{HT}+\mathrm{TiO}_{2}$ (b). Thickness ofthe MTC and PTC layers is $\sim 120 \mathrm{~nm}$, PCBM layer - 50 $\mathrm{nm}$ and Al-electrode $-70 \mathrm{~nm}$.

\section{RESULTS AND DISCUSSION}

To find out a wavelength range for excitation, absorption spectra in the UV-Vis range for the polymers were recorded. Fig. 2 shows the absorption spectra of pure polymers and polymeric composites. The absorption peak was found at $\sim 510 \mathrm{~nm}$ for MEH-PPV, whereas P3HThave two peaks at $495 \mathrm{~nm}$ and $528 \mathrm{~nm}$ and one shoulder at $573 \mathrm{~nm}$. These three bands can be attributed to the $p-p^{*}$ transition. These values were similar to the ones that have been reported for P3HT [10]. Polymeric composites (with the presence of $\mathrm{nc}^{-\mathrm{TiO}_{2}}$ particles) have almost the same absorption spectra, except one peak in ultra-violet $(360 \mathrm{~nm})$ of $\mathrm{TiO}_{2}$. Fig. 2 clearly shows that P3HT and its composite absorbed much larger range of wavelengths in comparison with MEH-PPV and its composite. Thus wavelengths around $500 \mathrm{~nm}$ were taken for excitation during PL measurements.

Fig. 3 shows the PL spectra of pure polymers and the polymer/nc- $\mathrm{TiO}_{2}$ films, all the measurements were carried-out at room temperature.For both two polymeric composites (namely MTC and PTC) the luminescence quenching of samples was observed at red wavelengths. For pure polymeric samples, the photoemission has a broad peak at $640 \mathrm{~nm}$ (for MEH-PPV) and $720 \mathrm{~nm}$ (for P3HT). For PTCsample thatcontains numerous $\mathrm{P} 3 \mathrm{HT} / \mathrm{nc}-\mathrm{TiO}_{2}$ heterojunctions, a blue shift of the photoemission peak of $\sim 25 \mathrm{~nm}$ was observed, whereas for the MTC, a negligible shift appeared. This blue shift is similar to the one for the hybrid sample of poly(para-phenylene vinylene) $(\mathrm{PPV}) / \mathrm{nc}-\mathrm{SiO}_{2}$ and was explained by a reduction in the polymer conjugation chain length, when nanoparticles of $\mathrm{SiO}_{2}$ were embedded in the polymer [11]. In our experiments, the polymer/ nc- $\mathrm{TiO}_{2}$ polymer was partially broken by the $\mathrm{TiO}_{2}$ nanoparticles. 


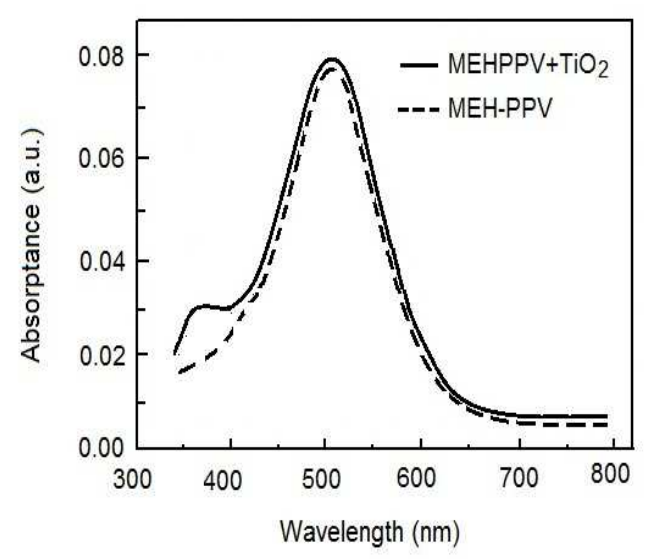

(a)

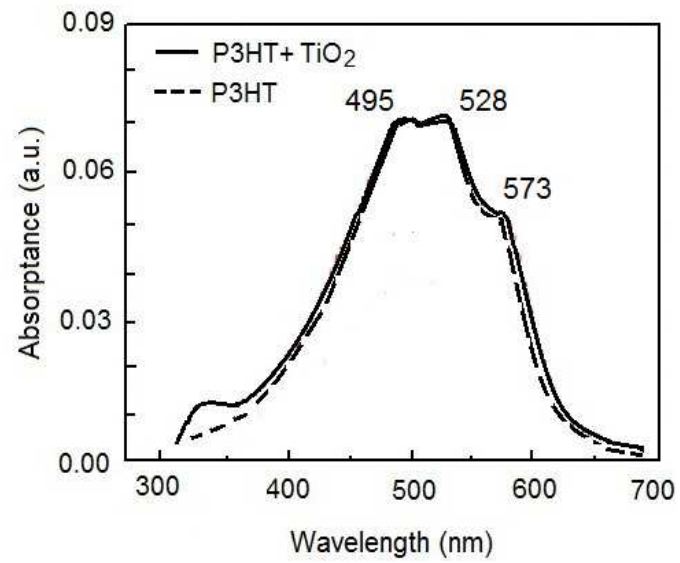

(b)

Fig. 2. The absorbance spectra of MEH-PPV and MEH-PPV+TiO 2 (a); P3HT and $\mathrm{P} 3 \mathrm{HT}+\mathrm{TiO}_{2}$ (b). Excitation wavelength $\lambda=500 \mathrm{~nm}$.
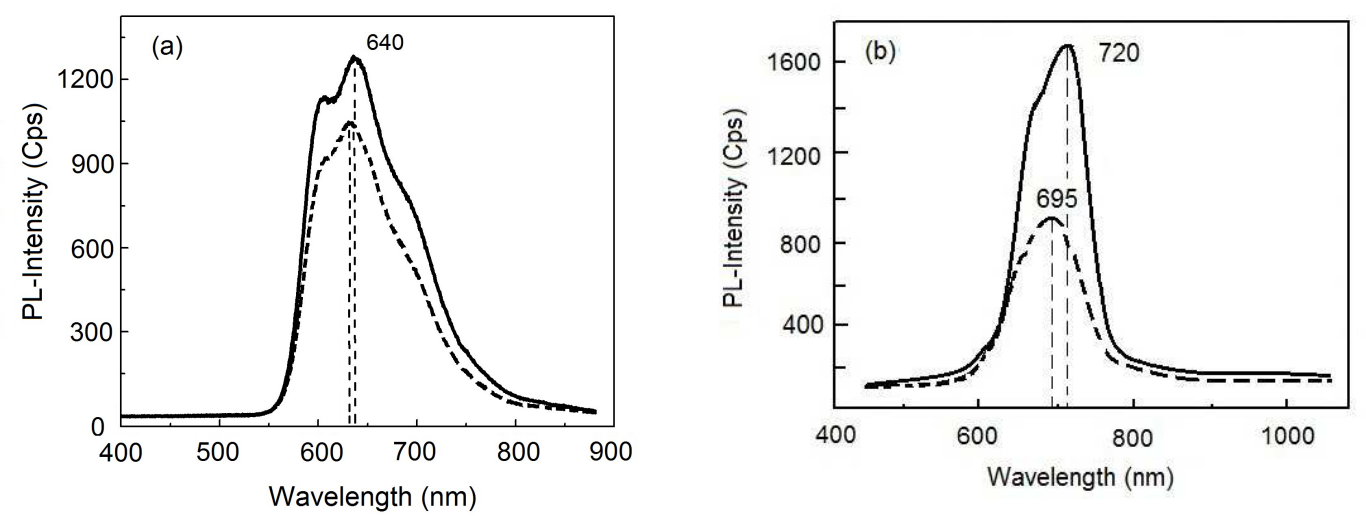

Fig. 3. (a): PL spectra of MEH-PPV and MEH-PPV/nc-TiO $2(5 \mathrm{~nm}) ;(b)$ : P3HT and $\mathrm{P} 3 \mathrm{HT} / \mathrm{nc}-\mathrm{TiO}_{2}(15 \mathrm{~nm})$.

To compare the quenching between MTC and PTC samples one can introduce a relative quenching coefficient $(\eta)$ that is calculated by following equation.

$$
\eta=\left(I_{p}-I_{c}\right) / I_{p}
$$

where $I_{p}$ and $I_{c}$ are the intensities of the PL peak of polymers and composites, respectively. From Fig. 3 and by applying the above equation, $\eta$ of MTC and PTC samples was found to be of $19.2 \%$ and $45.5 \%$, respectively. The result of the calculation shows that the quenching coefficient of PTC sample is more than two times larger than that of the MTC sample. Note that the size of nc- $\mathrm{TiO}_{2}$ particles embedded in $\mathrm{P} 3 \mathrm{HT}$ is three times larger than the size of $\mathrm{nc}^{-\mathrm{TiO}_{2}}$ embedded in MEH-PPV. Thus, the size of the quencher $\mathrm{TiO}_{2}$ nanoparticles influences the photoluminescence 
quenching of the polymeric composites. This matches the reported result in [12] for poly $(\mathrm{N}$ vinylcarbazole)(PVK) polymer containing Au nanoparticles. Thipperudrappa at all showed that the fractional intensity $I_{p} / I_{c}$ is given by the product of both static and dynamic quenching [13]. The authors also demonstrated that instantaneous or static quenching occurs if the quencher substances are very near to, or in contact with fluorescent molecules at the moment of its excitation. In other words, the electron-hole pairs generated at the heterojunctions (i.e. polymer $/ \mathrm{nc}-\mathrm{TiO}_{2}$ interfaces) are not recombined; they are separated from each other, resulting in the luminous quenching of polymeric composite thin films. This is a specific property that is desired for designing a simple, but prospective organic solar cell. The fact that the quenching is closely involved to the charge separation proves that the luminous quenching can be considered as a useful factor for choosing a combination of conducting polymers and inorganic nanoparticles used for OSCs fabrication.

In addition, the difference in quenching properties of the MTC and PTC samples can be explained by the use of the energy bandgap structures of the heterojunctions (Fig. 4). Herein, the energy values showed in the diagram are reported as absolute values relative to a vacuum levelof MEH-PPV [8] and P3HT [14].

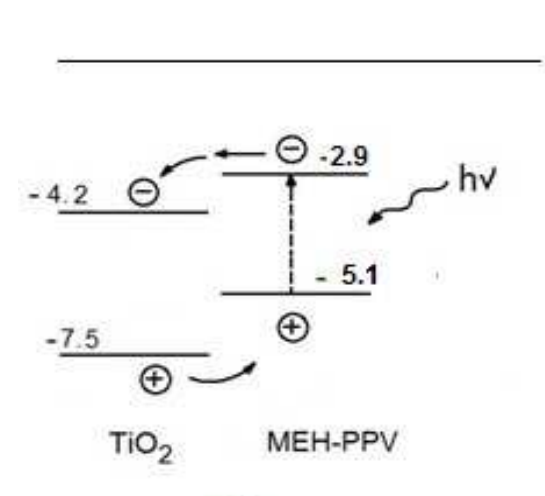

(a)

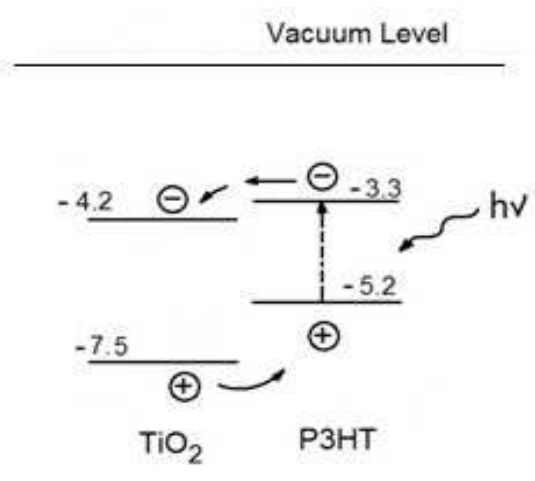

(b)

Fig. 4. Band structure diagram illustrating the HOMO and LUMO energiesof MEH-PPV (a) and $\mathrm{P} 3 \mathrm{HT}$ (b) relative to the band structure of $\mathrm{TiO}_{2}$.

The energy bandgap $\left(\mathrm{E}_{g}\right)$ of P3HT, MEH-PPV and $\mathrm{TiO}_{2}$ is $1.9,2.2$ and $3.3 \mathrm{eV}$, respectively. The difference between conducting band level of $\mathrm{TiO}_{2}$ and LUMO level of MEH-PPV and P3HT is $\Delta E_{1}=1.3 \mathrm{eV}$ and $\Delta E_{2}=0.9 \mathrm{eV}$, respectively (Fig. 4). When polymers were excited by a beam with energy larger than $E_{g}$ of polymers, generated electrons jumped from the HOMO to the LUMO and in the HOMO holes appeared. Since the conducting band level in $\mathrm{TiO}_{2}$ is lower than the LUMO level, electrons diffused to the conductor band of $\mathrm{TiO}_{2}$. On the contrary, holes moved from the valence band of $\mathrm{TiO}_{2}$ to the $\mathrm{HOMO}$ band of polymers, resulting in the charge separation. Since $\Delta E_{2}$ is much smaller than $\Delta E_{1}$, generated electrons move more easily to nc- $\mathrm{TiO}_{2}$. If the difference in energy between the conducting band level of $\mathrm{TiO}_{2}$ and $\mathrm{LUMO}$ level of polymer is large like $\Delta E_{1}$, one can use electron conducting buffer between them, similarly to $\mathrm{ZnO}$ that was used as buffer material sandwiched between ITO and PCBM, as reported in [15]. 
As mentioned above, OSCs based on MTC (OSC-1) and PTC (OSC-2) thin layers were made for a comparison of their performances. Characterization of the device parameters such as open voltage $\left(V_{O C}\right)$, short cut current density $\left(J_{S C}\right)$ and fill factor $(F F)$ was carried out with the Auto-Lab. potentiostat using cyclic voltammetry (CV) measurements in both the dark and illumination. In this case CV curves shown in Fig. 5 just revealed current-voltage (I-V) characteristics of two devices OSC-1 and OSC-2. In this figure the light-gray rectangle illustrates a fill factor that is determined by charge carriers reaching the electrodes, when the built-in field is lowered toward the open circuit voltage. In fact, there is a competition between charge carrier recombination and transport. So that, FF can be determined by:

$$
F F=\frac{(J \times V) \max }{J s c \times V o c}
$$

where $(J \times V)_{\max }$ is the rectangle having the largest area. Then the photoelectrical conversion efficiency (PCE) can be determined by:

$$
P C E=\frac{F F \times J s c \times V o c}{P_{i n}},
$$

where $P_{i n}$ is the density of the illuminating power, in $\mathrm{mW} / \mathrm{cm}^{2}$. In our experiments $P_{\text {in }}$ was taken at a value of $56 \mathrm{~mW} / \mathrm{cm}^{2}$.

By applying formulas (2) and (3), FFs of OSC-1 and OSC-2 were calculated and equal to 0.53 and 0.64 , respectively. And PCE of OSC- 1 and OSC- 2 was found to be of $0.17 \%$ and $0.45 \%$, respectively. It means that PCE of OSC-2 is more than two times larger than that of OSC-1.

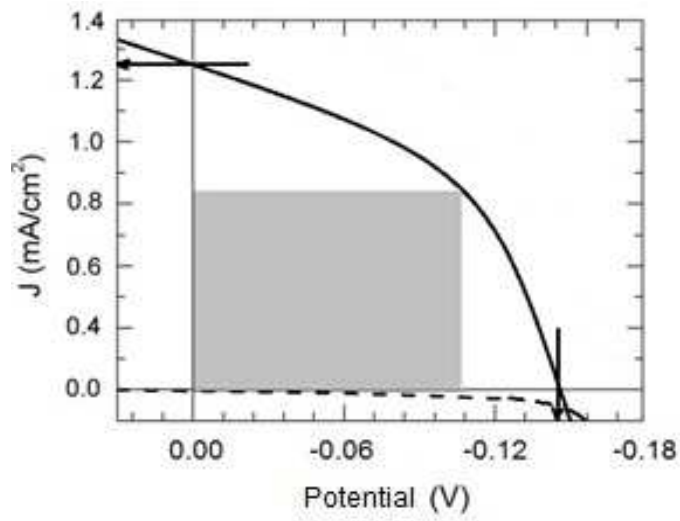

(a)

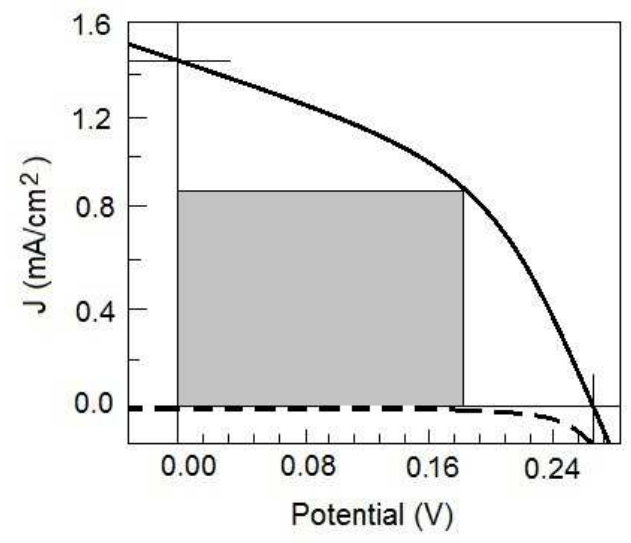

(b)

Fig. 5. Current-voltage characteristics of OSC-1(a): Pin $=56 \mathrm{~mW} / \mathrm{cm}^{2}$, Voc $=0.14 \mathrm{~V}$, Jsc $=1.24 \mathrm{~mA} / \mathrm{cm}^{2}, \mathrm{FF}=0.53, \mathrm{PCE}=0.17 \%$ and OSC-2 (b): Pin $=56 \mathrm{~mW} / \mathrm{cm}^{2}, \mathrm{Voc}=0.243$ $\mathrm{V}, \mathrm{Jsc}=1.43 \mathrm{~mA} / \mathrm{cm}^{2}, \mathrm{FF}=0.64, \mathrm{PCE}=0.45 \%$.

The fact that the fill factor of OSC-2 is larger than that of OSC-1 proves that in comparison with MEH-PPV, conducting polymer $\mathrm{P} 3 \mathrm{HT}$ is a better matrix where $\mathrm{nc}^{-\mathrm{TiO}_{2}}$ nanoparticles are more tightly surrounded. This is because during the spinning process in the spin-coating technique, the $\mathrm{TiO}_{2}$ nanoparticles can adhere by a strong electrostatic force to the polymer and between 
themselves, and capillary forces can then draw the P3HT solution around the inorganic nanoparticles into cavities without opening up pinholes through the device. Similar results were reported elsewhere [3]. The results obtained show that for a nanocomposite, the larger the quenching coefficient, the higher the photoelectrical efficiency is.

\section{CONCLUSION}

Nanocomposite materials containing heterojunctions of $\mathrm{MEH}-\mathrm{PPV}+\mathrm{nc}-\mathrm{TiO}_{2}$ and $\mathrm{P} 3 \mathrm{HT}+\mathrm{nc}-$ $\mathrm{TiO}_{2}$ were prepared by spincoating MEH-PPV and P3HT on ITO electrodes. Luminous quenching was observed for both polymeric composites, but the quenching coefficient of $\mathrm{P} 3 \mathrm{HT}+\mathrm{nc}-\mathrm{TiO}_{2}$ is much larger than that of $\mathrm{MEH}-\mathrm{PPV}+\mathrm{nc}-\mathrm{TiO}_{2}$. The results obtained on the relationship of $\mathrm{PL}$ quenching and photoelectrical efficiency of the OSC showed that the quenching coefficient can be seen as a useful criterion for choosing appropriate polymers and inorganic nanoparticles being used for the further preparationof OSCs.Under an illumination of solar energy of $56 \mathrm{~mW} / \mathrm{cm}^{2}$, photoelectrical efficiency $\mathrm{P} 3 \mathrm{HT}+\mathrm{nc}-\mathrm{TiO}_{2}$ based $\mathrm{OSC}$ reached a value of $0.45 \%$.

\section{ACKNOWLEDGEMENTS}

This research was funded by the Vietnam National Foundation for Science and Technology (NAFOSTED) under grant number 103.02-2013.39.

Infrastructure and equipment provided for samples preparation, FE-SEM, XRD patterns, absorption and PL spectra, solar cells performance measurements were made possible in the VNU project on "Nanotechnology and Application" supported by the Vietnamese Government.

\section{REFERENCES}

[1] C. J. Brabec, N. S. Sariciftci, J. C. Hummenmen. Plastic solar cell. Adv. Funct. Mater. 11 (2001) 15.

[2] H. Hoppe, N. S. Sariciftci, J. Mater. Research 19(7) (2004) 1724.

[3] S. A. Carter, J. C. Scott, J. Brock, J. Appl. Phys. 71(9) (1997) 1145.

[4] S. A. Choulis, M.K. Mathai, V.E. Choong, Appl. Phys. Lett. 213 (2006) 503.

[5] A. A. Madhavan, G. G. Kumar, S. Kalluri, J. Joseph, S. Nagarajan, S. Nair, K. R. V. Subramanian, A. Balakrishnan, J. Nanosci. Nanotechnol. 12 (2012) 7963.

[6] B. C. Thompson, J. M. J. Frehet, Angew. Chem. Int. Ed. 47 (2008) 58.

[7] F. A. Castro, H. Benmansour, J. E. Moser, C. F. O. Graeff, F. Nüesch, and R. Hany, Phys. Chem. Chem. Phys. 11 (2009) 8886.

[8] S. Ren, L. Y. Chang, S. K. Lim, J. Zhao, M. Smith, N. Zhao, V. Bulovic, M. Bawendi, S. Gradecak, Nano Letters 11 (2011) 3998.

[9] P. M. Allemand, A. Koch, F. Wudl, Y. Rubin, F. Diederich, M. M. Alvarez, S. J. Anz, and R. L. Whetten, J. Am. Chem. Soc. 113 (1991) 1050.

[10] V. Shrotriya, J. Quyang, R. J. Tseng, G. Li, Y. Yang, Chem. Phys. Lett. 411 (2005) 138.

[11] S. H. Yang, T. P. Nguyen, P. Le Rendu, C. S. Hsu, Composites Part A: Appl. Sci. Manufact. 36 (2005) 509.

[12] S. Bhattacharyya, A. Mitavapatra, Bull. Mater. Sci. 35 (2012) 719.

[13] J. Thipperudrappa D. S. Biradar, and S. M. Hanagodimath, J. Lumin. 124 (2007) 45.

[14] C. Y. Kuo, W. C. Tang, C. Gau, T. F. Guo, D. Z. Jeng, Appl. Phys. Lett. 93 (2008) 033303.

[15] B. Freisinger, Investigation of P3HT/PCBM Particle-Based Solar Cells, Ph.D. dissertation, Mainz, FRG - 2013, p. 168. 